\title{
Melatonin-independent Photoperiodic Entrainment of the Circannual TSH Rhythm in the Pars Tuberalis of the European Hamster
}

\author{
Cristina Sáenz de Miera,,'1 (DDominique Sage-Ciocca, ${ }^{+}$Valérie Simonneaux, ${ }^{*}$ Paul Pévet, \\ and Stefanie Monecke ${ }^{*}, 2$ \\ "Department of Neurobiology of Rhythms, Institute for Cellular and Integrative Neuroscience, \\ University of Strasbourg, Strasbourg, France, and ${ }^{+}$Chronobiotron UMS3415-CNRS, \\ University of Strasbourg, Strasbourg, France
}

\begin{abstract}
Adaptation of biological rhythms to a seasonal environment in circannual mammals is achieved via the synchronization of intrinsic circannual rhythms to the external year by photoperiod. In mammals, the photoperiodic information is integrated to seasonal physiology via the pineal hormone melatonin regulation of pars tuberalis (PT) TSH $\beta$ expression and its downstream control of hypothalamic dio2 gene expression. In the circannual European hamster, however, photoperiodic entrainment of the circannual clock is possible in pinealectomized animals. The present study explores whether the TSH $\beta$ expression in the PT and the downstream hypothalamic pathways are regulated by photoperiod in European hamsters in the absence of melatonin. All animals were kept on an accelerated photoperiodic regime, which compressed the natural year to a 6-month cycle. Sham-operated European hamsters and half of the pinealectomized European hamsters entrained their annual cycle in reproduction, body weight, and activity pattern to this cycle, whereas the other half of the pinealectomized animals followed only each second cycle. In all animals, PT TSH $\beta$ and hypothalamic dio2 expressions were higher in hamsters displaying a summer physiological state than in those in winter state. Moreover, in agreement with their seasonal state, reproductive animals (summer state) showed higher expression of $r f r p$ and lower expression of kiss1-genes encoding central regulators of the reproductive axis-than those animals in reproductive quiescence (winter state), indicating the hypothalamic integration of the photoperiodic signal even in pinealectomized animals. The appropriate occurrence of a well-characterized activity pattern indicative of a so-called sensitive phase to short photoperiod suggested that the SCN constructs the melatonin-independent photoperiodic message. This message is sufficient to entrain the circannual rhythm in TSH $\beta$ expression in the PT and the downstream hypothalamic neuroendocrine pathway through a yet unknown pathway. These results reinforce the hypothesis that the PT is the site for the integration of circannual and photoperiodic information.
\end{abstract}

1. To whom all correspondence should be addressed: Cristina Sáenz de Miera, Department of Molecular, Cellular, and Developmental Biology, The University of Michigan, 830 N. University, Ann Arbor, MI 48109, USA; e-mail: cristinasaenzdemiera@gmail.com.

2. Current addresses: Institute of Chronoecology, Stuttgart, Germany, and Ludwig Maximilians University, Institute of Medical Psychology, Munich, Germany. 
Keywords circannual rhythm, melatonin, photoperiodic entrainment, pars tuberalis, TSH, deiodinase 2, rfrp, kisspeptin, Cricetus cricetus

Animals living in environments with seasonal variations need to appropriately integrate and interpret environmental cues in order to optimize the synchronization of their biological functions to the external year. Many organisms have evolved intrinsically generated circannual rhythms, which drive seasonal transitions in physiology and behavior, allowing anticipation to upcoming changes in the environmental conditions (Pengelley and Asmundson, 1974; Gwinner, 1986; Karsch et al., 1989; Nisimura and Numata, 2001). Although circannual rhythms were described some time ago, the site of the "circannual clock" at the origin of the circannual oscillations remains unknown. Circannual rhythms typically present an endogenous period slightly different from the astronomical year (Gwinner, 1986) and thus need to be synchronized by a precise environmental cycle for success in keeping track of time. The most reliable cue for the changes in season is the annual change in day length or photoperiod.

In mammals, the photoperiodic information is encoded in the suprachiasmatic nucleus (SCN), where the change in light duration modifies the phase relationship between clock genes (NuessleinHildesheim et al., 2000). From here, the photoperiodic message is conveyed to the pineal gland via a multisynaptic pathway that ends by sympathetic inhibition of pineal melatonin synthesis during the light phase (Moore, 1996; Perreau-Lenz et al., 2004). Thus, the nocturnal message of the pineal hormone melatonin provides the organism with an internal representation of the photoperiodic message, since its duration varies in agreement with the night length. The circulating melatonin signal is principally relayed by the melatonin receptor-rich pars tuberalis (PT) of the pituitary gland to control seasonal physiology (Skene et al., 1993; Lincoln and Clarke, 1994; Dardente et al., 2003). Here, the long melatonin peak associated with winter short photoperiod (SP) inhibits the expression of the $\beta$ subunit of thyroid stimulating hormone (TSH $\beta$ ), while the short duration of the melatonin peak in long photoperiod (LP) in the summer allows TSH $\beta$ synthesis and thus TSH production and release from the PT (Böckers et al., 1995; Dardente et al., 2003, 2010).

When the circannual European hamster (Cricetus cricetus) is pinealectomized and maintained under constant LP, the endogenous circannual timing signal itself regulates PT TSH $\beta$ expression (Sáenz de Miera et al., 2014). An endogenous variation in PT TSH $\beta$ expression has been also observed in Soay sheep undergoing spontaneous changes in reproductive physiology, but in the presence of melatonin (Sáenz de Miera et al., 2013; Wood et al., 2015). Recently, endogenous long-term regulation of transcription factors controlling TSH $\beta$ gene transcription has been discovered within the PT thyrotroph cells in sheep (Wood et al., 2015), adding evidence to a hypothesis suggesting that the PT could also be the site for the circannual clock itself (reviewed in Wood and Loudon 2018). Altogether, these findings suggest that melatonin acts on the PT to synchronize the endogenous circannual message to the photoperiodic signal. The PT is thus an essential site for orchestrating seasonal variations in biological functions (Sáenz de Miera et al., 2014; Lomet et al., 2018).

The seasonal TSH signal coming from the PT is relayed to the hypothalamus, where it binds to its receptor present in the tanycytes (Hanon et al., 2008), glial cells situated on the wall of the third ventricle. In the tanycytes, TSH promotes the expression of thyroid hormone deiodinase 2 (dio2), whose role is to transform the circulating form of thyroid hormone, thyroxine, into its bioactive form, triiodothyronine (T3), therefore increasing the local level of T3 (Hanon et al., 2008; Klosen et al., 2013). Hypothalamic T3 plays a key role in the regulation of seasonal physiological state; high hypothalamic T3 content is associated with the initiation and maintenance of summer physiology (Barrett et al., 2007; Dardente et al., 2014).

In the specific seasonal control of the reproductive axis, the LP-induced increase in TSH and dio2 is associated with a marked regulation of the neuropeptides RFamide-related peptide (RFRP) in the dorsomedial and ventromedial hypothalamic area (DMH/VMH) and kisspeptin (Kiss) in the arcuate nucleus (ARC) (Klosen et al., 2013). Both neuropeptides regulate GnRH neuronal activity and are therefore involved in the central control of reproduction (Vogel, 2005; Tsutsui et al., 2010). The level of RFRP gene expression in the DMH/VMH is always higher in LP than in SP whether animals are long-day or short-day breeders (Smith et al., 2008; Ancel et al., 2012; Ubuka et al., 2012; Henningsen et al., 2016). In addition to photoperiod, kisspeptin neurons are regulated by numerous signals including sex-steroid feedback and metabolic cues; therefore, the seasonal variation of kisspeptin gene expression displays species-specific differences (Revel et al., 2006; Smith et al., 2009; Ansel et al., 2010; Talbi et al., 2016; Rasri-Klosen et al., 2017). The photoperiodic control of seasonal breeding is mediated by the melatonin-driven TSH regulation of hypothalamic RFamide peptides (Simonneaux et al., 2013). Notably, the same hypothalamic neuroendocrine pathway has 
been shown to be involved in the transmission of the endogenous circannual timing signal in circannual mammals, both long-day and short-day breeders (Sáenz de Miera et al., 2013, 2014).

Previous studies in European hamster disclosed that in this species, the circannual clock is mainly reset (Monecke et al., 2009) by the photoperiodic information at two phases of sensitivity to LP and SP, respectively (Saboureau et al., 1999; Monecke and Wollnik, 2004). During the phase of sensitivity to SP, the melatonin rhythm is absent (Vivien-Roels et al., 1997; Monecke and Wollnik, 2005), whereas during the phase of sensitivity to LP, melatonin receptor expression in the PT is profoundly reduced (Dardente et al., 2003), suggesting that photoperiodic entrainment can occur without melatonin. Indeed, photoperiod is able to entrain circannual rhythms in pinealectomized European hamsters, indicating that the photoperiodic signal can synchronize the circannual clock independently of the melatonin signal (Monecke et al., 2013; Monecke et al., 2014b). Together, these findings suggest the existence of a melatoninindependent pathway through which the photoperiodic information from the SCN entrains the circannual message governing seasonal physiology.

To characterize the neuroendocrine level at which photoperiodic melatonin-independent input entrains the circannual reproductive cycle, we explored the hypothesis that this pathway is mediated via TSH expression in the PT and is hence transmitted to the reproductive axis by the hypothalamic neuroendocrine pathway described for the melatonin-dependent and circannual seasonal inputs. For this purpose, we studied the expression of the genes involved in transducing the photoperiodic melatonin message in the PT and the hypothalamus (TSH $\beta$, dio2) and of those involved in the central control of reproduction (rfrp and kiss1) in European hamsters maintained under an accelerated photoperiodic cycle, expressing either a summer or a winter state in their reproductive physiology. Our results indicate that a melatonin-independent photoperiodic signal entrains the circannual TSH $\beta$ expression in the PT and the downstream genes involved in seasonal physiology.

\section{MATERIALS AND METHODS}

\section{Animals and Experimental Design}

All experiments were performed in accordance with the National Institutes of Health guidelines for the care and use of animals in experimental procedures, with the European Communities Council Directive of November 24, 1986 (86/609/EEC), and with French laws. This study was performed using 23 male European hamsters born in our breeding colony at the Chronobiotron (CNRS-UMS3415). These animals were part of "group 2010" described by Monecke et al. (2013). From birth, the animals were maintained at $20^{\circ} \mathrm{C}$ under a 16-h light and 8-h dark (LD16:8) photoperiodic cycle and were transferred to an accelerated photoperiodic regime at the age of 3 months when the accelerated photoperiod was at its maximum (LD16:8). The accelerated photoperiod mimicked the natural changes in photoperiod with double speed so that one complete cycle was terminated within 6 months. This accelerated cycle allowed us to observe a larger number of cycles per animal, and its shorter period clearly differs from the endogenous circannual period length (Monecke et al., 2013). The animals were either pinealectomized or sham-operated at the age of 9 months when the photoperiod was about LD15.5:8.5 - that is, shortly after the maximum photoperiod, when melatonin production is negligible (Vivien-Roels et al., 1997).

Animals were classified into 3 groups according to the presence or absence of melatonin and their entrainment to the photoperiodic regime. The first group was the control group $(n=8)$, which consisted of sham-operated animals that entrained (see below) to the accelerated photoperiodic regime of 6 months. The second group consisted of pinealectomized animals (Px; $n=7)$ that also entrained to the accelerated photoperiodic cycle. The third group, the "pinealectomized nonentrainers" (Px-NE; $n=8)$, consisted of pinealectomized animals that did not entrain to each cycle but rather to each second cycle of the accelerated photoperiodic regime. More information about the characteristics of entrainment is given in the Results section.

\section{Pinealectomy}

The animals were anesthetized with an intraperitoneal injection of $0.2 \mathrm{~mL} / 100 \mathrm{~g}$ body weight of a mixture of 4 volumes Zoletil 20 (Virbac, Carros, France) and 1 volume Rompun (Bayer HealthCare, Leverkusen, Germany). According to a method described by Hoffman and Reiter (1965), a circular bone disk was cut out around the lambda. The superior sagittal sinus underneath was perforated with pointed forceps so that the subjacent pineal gland could be seized and removed. During surgery, blood was continuously removed by a vacuum pump. Bleeding was stopped with gel foam (Bloxang; Bausch and Lomb, Aubenas, France), and the bone disk, which was kept in Ringer solution in the meantime, was reinserted. At the end of the surgery, the animals received a subcutaneous injection of 2 to $4 \mathrm{~mL}$ of warm Ringer solution to replace blood loss. For sham surgery, the circular bone disc was removed and reinserted. 
The success of pinealectomy or sham surgery was verified by (1) histological investigation of the removed tissue, (2) postmortem inspection of the cranial cavity, and (3) measurement via radioimmunoassay of the melatonin content in blood (Vivien-Roels et al., 1992) collected at 2 occasions, shortly after the following shortest and longest photoperiod at 3 circadian times each. The detailed results of the blood sampling are given in Monecke et al. (2013). The pinealectomy was successful in all pinealectomized animals.

\section{Seasonal Markers}

Three physiological parameters were monitored to track the endogenous physiological state of the animals and their entrainment to the accelerated photoperiodic cycle. Body weight of all animals was monitored every second week, as well as their reproductive state, assessed by measuring scrotal testicular length under short isofluorane anesthesia. Locomotor activity was recorded in 5-min intervals by infrared captors using CAMS (Circadian Activity Monitoring System; Howard Cooper, INSERM, France). The parameters used to assign animals to a physiological state at the time of sacrifice were precisely as described by Monecke et al. (2013). Briefly, an animal was considered to be in the summer state when the maximum increase in body weight during a cycle was observed, when testis size was larger than $1.8 \mathrm{~cm}$, and when the animal showed the summer pattern in activity characterized by a precise rhythm and high activity levels, determined by the crossing of the running average of the day-to-day variations in the activity onset with a set threshold at a variability of $2 \mathrm{~h}$. An animal in the winter state showed the maximum decrease in body weight during a cycle, regressed testes, and an arrhythmic activity pattern.

\section{Sampling and Tissue Collection}

In the present experiment, the zeitgeber (photoperiod) period $(\mathrm{T})$ was clearly shorter than the endogenous (circannual) period $(\tau)$ of the animals. Under these conditions, entrainment takes place with a negative phase angle $(\varphi)$ to the fast environmental cycle (Johnson et al., 2004). Therefore, we sampled the animals when they expressed the desired winter or summer seasonal physiology, shortly after (and not at) the "solstices" (i.e., the minimum or maximum photoperiod, respectively). Half of the animals of each group were sacrificed 10 months after surgery shortly after the minimum photoperiod (LD8:16) had passed. At this stage, all sacrificed animals presented winter physiology (sexual quiescence, body weight decrease, arrhythmic activity pattern) and thus formed the "winter" subgroups (Figs. 1 and 2). However, because the date of sacrifice was the same for all the animals, the time they spent in this physiological state was different between animals of the Px-NE group (already 5-6 months in the winter state, since they skipped the second reproductive phase) and animals of the Px and control groups (about 2 months in winter physiology). The remaining half of the animals were sacrificed 3 months later, shortly after the maximum photoperiod (LD16:8). At this sampling point, all animals expressed summer physiology (reproductive phase, body weight increase, rhythmic activity pattern) and thus were considered as "summer" subgroups (Figs. 1 and 2). Similar to what happened in the winter subgroup animals, the animals in the Px-NE group initiated the summer state earlier than the Px and control animals, because of their entrainment to every second cycle. At the date of sacrifice, Px-NE animals had been in the summer physiological state 1 to 2 more months than the Px and control animals.

Animals were euthanized by $\mathrm{CO}_{2}$ saturation. Immediately after death and blood collection by cardiac puncture, tissues were fixed by transcardiac perfusion first with phosphate saline solution (PBS) 0.1 $\mathrm{M}$ and then with $4 \%$ paraformaldehyde (PFA) in 0.1 $\mathrm{M}$ phosphate buffer (PB), $\mathrm{pH}$ 7.4. Brains were dissected off the skull, postfixed in the same fixative for $24 \mathrm{~h}$, dehydrated in serial alcohols, stored in butanol, and embedded in polyethylene glycol (Klosen et al., 1993). Brains were sliced into $14-\mu m$-thick coronal sections using a microtome (Leica Microsystems $\mathrm{GmbH}$, Wetzlar, Germany). One in 10 coronal brain sections through the hypothalamus were mounted on SuperFrost ultraplus slides (Menzel-Glaser, Braunscheig, Germany) and stored at $-80{ }^{\circ} \mathrm{C}$ until processed for in situ hybridization.

\section{Nonradioactive In Situ Hybridization}

Antisense rat riboprobes were used for detection of kiss1 (Ansel et al., 2010) and TSH $\beta$ (Dardente et al., 2003) mRNA. Rfrp and dio2 expression were analyzed using antisense Siberian hamster riboprobes (Klosen et al., 2013) as in Sáenz de Miera et al. (2014). Briefly, probes were digoxigenin (DIG) labeled, according to the manufacturer's instructions (Roche, Meylan, France). Brain sections were postfixed in PFA $4 \%$ in phosphate buffer for $10 \mathrm{~min}$ at room temperature, rinsed with PBS, treated with 0.5 to $1 \mu \mathrm{g} / \mu \mathrm{L}$ proteinase $\mathrm{K}$ (Roche) for $30 \mathrm{~min}$ at $37^{\circ} \mathrm{C}$, rinsed with ice-cold PFA $2 \%$ in phosphate buffer, rinsed again in PBS, acetylated twice for $10 \mathrm{~min}$ with $0.25 \%$ acetic anhydride in $100 \mathrm{mM}$ triethanolamine, and finally equilibrated in $5 \times$ salinesodium citrate (SSC) $0.05 \%$ TW20 twice for $5 \mathrm{~min}$ at room temperature. Hybridization was performed with 


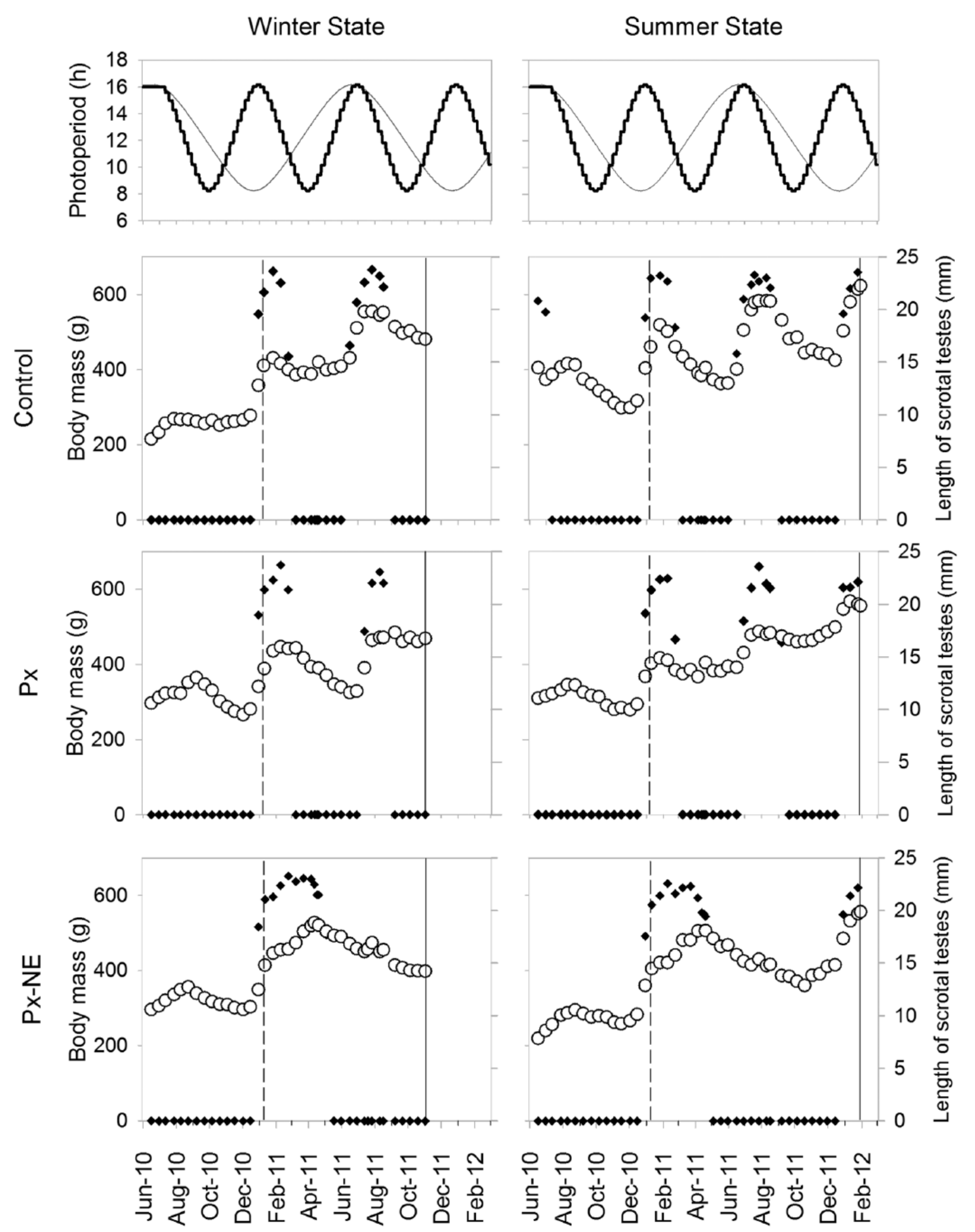

Figure 1. Seasonal changes in physiological parameters of the male European hamsters kept in an accelerated photoperiod. Top graphs: Accelerated photoperiodic schedule (black) along the experiment and, for comparison, natural changes in photoperiod (gray) at $48^{\circ} 40^{\prime} \mathrm{N}$. Individual representative graphs for body mass (white circles) and right testis size (black diamonds) of the sham-operated animals (control), pinealectomized entrainers (Px), and pinealectomized nonentrainers (Px-NE) sampled at the winter or summer state. The sampling points in each group are marked by a dark gray vertical line crossing the graph. The date of surgery is marked by a dashed vertical line crossing the graphs. The entrainment state for the reproductive state of all individual animals in this experiment can be found in Figure 2 of Monecke et al. (2013). 

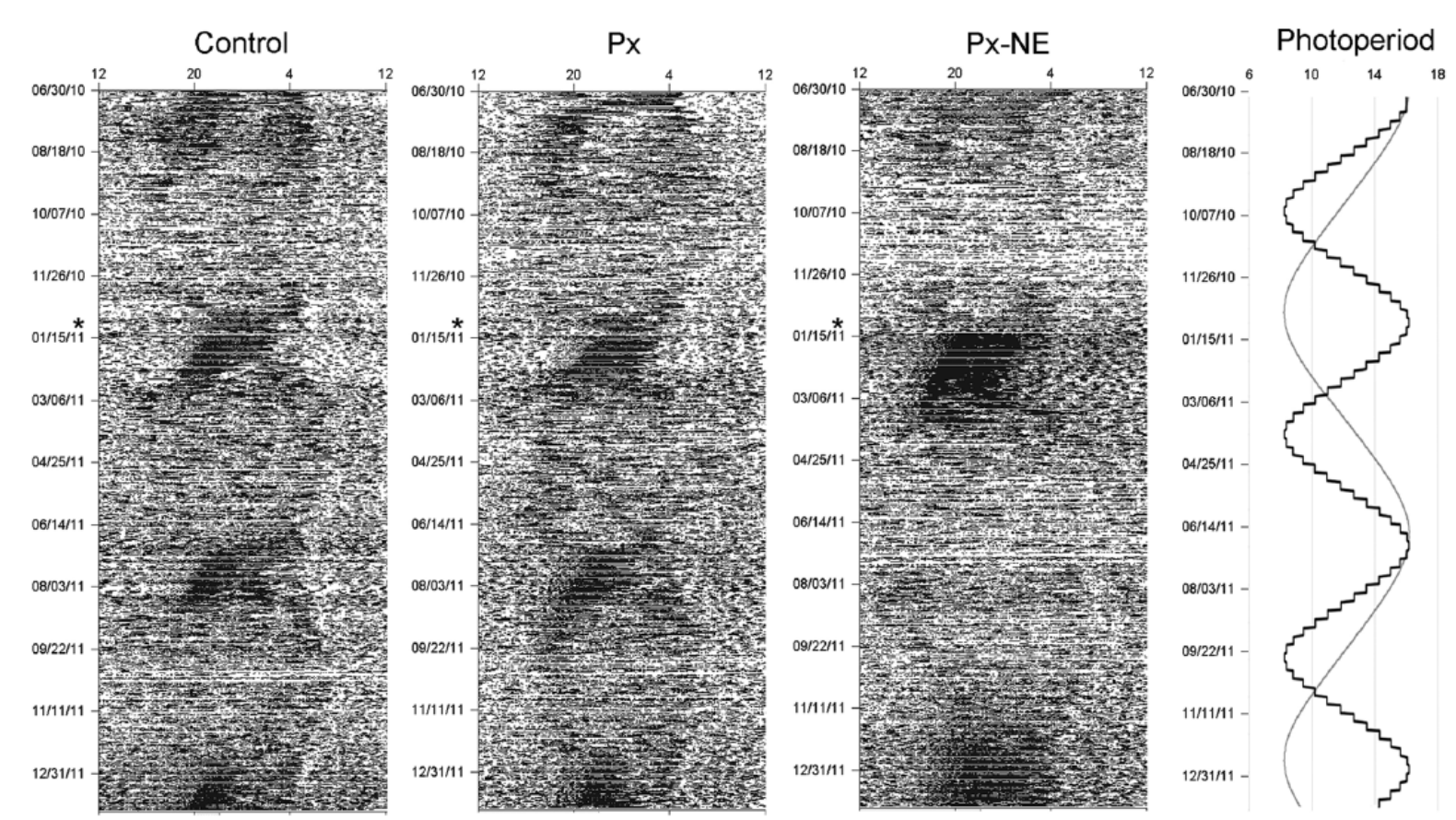

Figure 2. Representative actograms of animals kept in an accelerated photoperiodic regime. Right panel: Accelerated photoperiodic schedule (black) along the experiment and, for comparison, natural changes in photoperiod (gray) at $48^{\circ} 40^{\prime} \mathrm{N}$. The actograms of a shamoperated control animal (left) and of a pinealectomized (Px) animal (center) showed seasonal entrainment to every phase of this accelerated photoperiodic regime with a negative seasonal phase angle by expressing a summer rhythmic pattern with high activity levels shortly after each peak in photoperiod. The actogram of a pinealectomized nonentrainer (Px-NE) animal (right) showed a longer summer pattern after the pinealectomy $\left(^{*}\right)$ followed by an arrhythmic winter pattern lasting about 6 months, thus skipping one summer pattern compared with the other groups.

$2 \mu \mathrm{g} / \mathrm{mL}$ antisense probe in a medium containing $50 \%$ formamide, $5 \times$ SSC, $5 \times$ Denhardt solution, $0.1 \%$ TW20, and $1 \mathrm{mg} / \mathrm{mL}$ salmon sperm DNA for $40 \mathrm{~h}$ at $60^{\circ} \mathrm{C}$. High stringency washes were performed with $0.1 \times$ SSC $0.05 \%$ TW 20 at $72{ }^{\circ} \mathrm{C}$ to reduce nonspecific labeling. Hapten-labeled riboprobes were detected using an alkaline phosphatase-labeled anti-DIG antibody (Roche). The alkaline phosphatase activity was detected with nitroblue tetrazolium and bromo-chloroindolyl phosphate. After detection, slides were premounted using Crystal mount aqueous mounting medium (Sigma-Aldrich, Lyon, France) and mounted with Eukitt (Sigma-Aldrich).

\section{Semiquantitative Analysis}

For TSH $\beta$ and for dio 2 analyses, photos were taken at $40 \times$ and at $100 \times$ magnification, respectively, using a Leica DMRB microscope (Leica Microsystems) fitted with an Olympus DP50 digital camera (Olympus, Hamburg, Germany), and digital images were produced using the software Viewfinder Lite (Olympus). Labeling intensity was calculated using IMAGEJ software (NIH, Bethesda, MD). For each slide, a background value was measured and was subtracted from the labeling measure. For dio2 analysis, the quantification was made using the "segmented line" tool of ImageJ, by drawing a line of approximately $150 \mu \mathrm{m}$ length and $7 \mu \mathrm{m}$ width that covered the staining along the periventricular zone of the third ventricle (PVZ). For TSH $\beta$ analysis, a polygon was drawn around the PT, and the mean intensity of staining over a threshold gray value of 15 was quantified within the polygon. Three consecutive sections along the rostrocaudal axis were measured per animal. The mean gray value in arbitrary units for each animal was calculated as the average of the 3 measurements.

Labeled neurons for kiss1 and rfrp mRNA were hand-counted using a Leica DMRB microscope (Leica Microsystems) by a person blinded to the experimental groups. For each animal, the number of neurons expressing kiss1 and $r f r p$ mRNAs was counted in all sections covering their rostrocaudal hypothalamic expression in the ARC and the $\mathrm{DMH} / \mathrm{VMH}$, respectively. For each peptide and for each experimental condition, data are given as the mean value of labeled neurons per animal.

\section{Data Analysis}

All data were analyzed by 2-way ANOVA with seasonal state and melatonin presence as independent 
factors followed by a post hoc Bonferroni test when appropriate. Pearson correlation analyses were used to evaluate relations between expressions of different genes. The threshold for statistical significance was set at $p<0.05$. All statistical analyses and body weight and testis size curves were performed using SigmaPlot version 12 (Systat Software Inc., San Jose, CA). Graphs were designed using GraphPad Prism version 6 (GraphPad Software Inc., La Jolla, CA) or Adobe Photoshop Elements 11 (Adobe Systems Inc., San Jose, CA). Activity data were analyzed using ClockLab (ActiMetrics, Wilmette, IL) and Microsoft Excel (Microsoft, Redmond, WA).

\section{RESULTS}

\section{Seasonal Physiology}

The animals were sacrificed shortly after the maximum or the minimum length of the accelerated photoperiodic cycle. At the time of sampling, no significant differences in body weight were found between groups, but there was a clear effect of season within the groups $\left(F_{1,17}=27.21 ; p<0.001\right)$ (control, summer $590 \pm 12.54 \mathrm{~g}$ and winter $447.5 \pm 34.04 \mathrm{~g}$; Px, summer $515.5 \pm 24.73 \mathrm{~g}$ and winter $457 \pm 59.19 \mathrm{~g}$; Px-NE, summer $529.8 \pm 11.26 \mathrm{~g}$ and winter $351.8 \pm$ $30.29 \mathrm{~g})$. However, due to interindividual differences in body weight, the curve trajectory of the individual rather than its final body weight is used as seasonal marker (Fig. 1). Animals of the winter state groups had body weight curves at their trough together with fully regressed gonads, while animals of summer groups had body weight curves at their peak and presented large descended testes, which did not differ in size between groups (Fig. 1).

\section{Entrainment}

All animals in the control and Px groups entrained in all 3 parameters to all phases of the accelerated photoperiodic regime; however, this occurred with a negative seasonal phase angle due to the fast environmental cycle. They became reproductive around the maximum photoperiod and not around the equinox as in 1-year cycles (Monecke and Wollnik, 2005). Likewise, the maximum daily increase in body weight, which occurs in natural conditions in early spring (Monecke and Wollnik, 2005), took place at the maximum length of the accelerated photoperiodic cycle (Fig. 1). Finally, the characteristic sudden switch from an arrhythmic to a highly rhythmic activity pattern with high activity levels-so-called "summer pattern" (Monecke and Wollnik, 2005)_occurred only at the maximum photoperiod and not 6 weeks before the longest day (Fig. 2).

The Px-NE group also presented entrainment in all 3 parameters; however, the animals entrained to each second summer phase of the accelerated cycle, remaining in the winter phase for up to 6 months. At sampling, the 3 physiological parameters of the Px-NE animals, which cycled synchronously along the whole experiment, were again in phase with the photoperiodic regime and the cycles of the control and Px groups (Figs. 1 and 2).

\section{TSH and Dio2 Expression Is Related to Photoperiod and Physiological State}

TSH $\beta$ gene expression in the PT was strongly regulated by the seasonal state at which animals were sampled $\left(F_{1,17}=99.19 ; p<0.0001\right.$; Fig. 3A). Higher TSH $\beta$ mRNA level was observed in animals sampled during the summer than during the winter states in the 3 groups (control, $t=5.504, p<0.001 ; \mathrm{Px}, t=4.717$, $p<0.001$; Px-NE, $t=7.124, p<0.001$ ). A difference in TSH $\beta$ gene expression by entrainment state was observed $\left(F_{2,17}=4.103 ; p=0.035\right)$; however, it concerned only Px and Px-NE animals within the summer state groups $(t=2.823, p=0.035)$. This suggests that the regulation of TSH $\beta$ gene expression in the PT is a key element of the integration of the photoperiodic message even in the absence of melatonin.

Next, dio2 mRNA level in the PVZ was higher in animals sampled in the summer than in the winter state $\left(F_{1,17}=16.841 ; p<0.001\right.$; Fig. 3B) but it was not influenced by the absence of melatonin or by the entrainment state $\left(F_{2,17}=0.521 ; p=0.603\right)$. Within groups, higher dio2 gene expression was observed in the summer than in the winter state groups ( $\mathrm{Px}, t=2.074$, $p=0.01 ; \mathrm{Px}-\mathrm{NE}, t=2.196, p=0.042$; control, $t=1.964$; $p=0.06)$. Dio 2 and TSH $\beta$ mRNA levels were strongly positively correlated (Pearson $r=0.70 ; p<0.001$, Fig. 3C). These results suggest that dio 2 mRNA level, similar to TSH $\beta$ mRNA level, is affected by the photoperiodic message even in the absence of melatonin.

\section{RFamide Gene Expression Matches the Seasonal State of the Animals}

To further investigate the integration of the accelerated photoperiodic signal into the central reproductive axis in the absence of the pineal hormone melatonin, we studied $r f r p$ and kiss1 gene expression. The number of rfrp-expressing cells in the DMH/ VMH area was markedly dependent on the season at which the animals were sampled $\left(F_{1,17}=41.63 ; p<0.0001\right.$; Fig. 4A) but was not dependent on melatonin or entrainment state $\left(F_{2,17}=1.30 ; p=0.298\right)$. All 3 groups 
A

TSHß

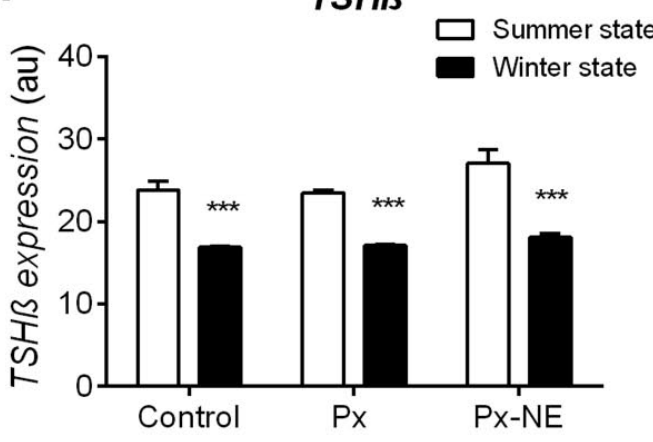

B

Dio2

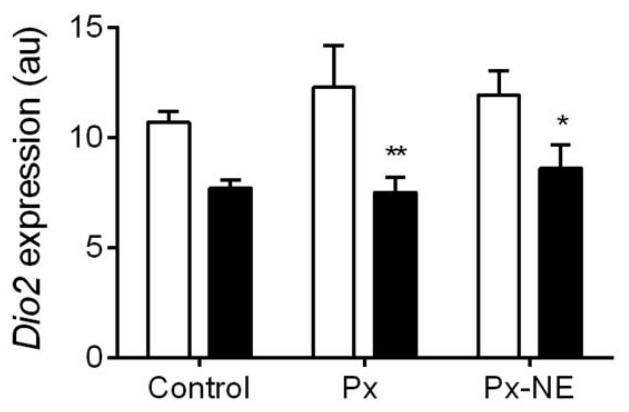

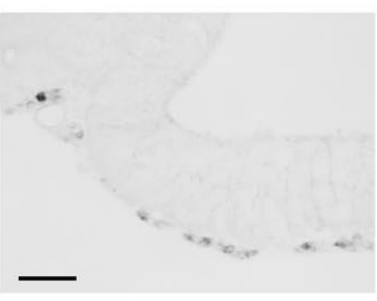

Summer

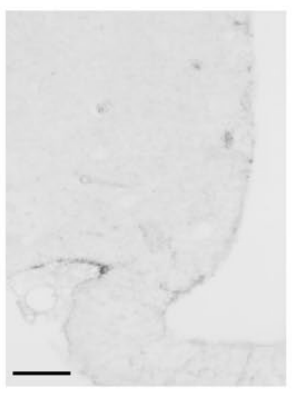

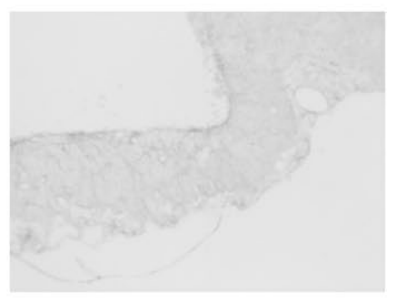

Winter

C

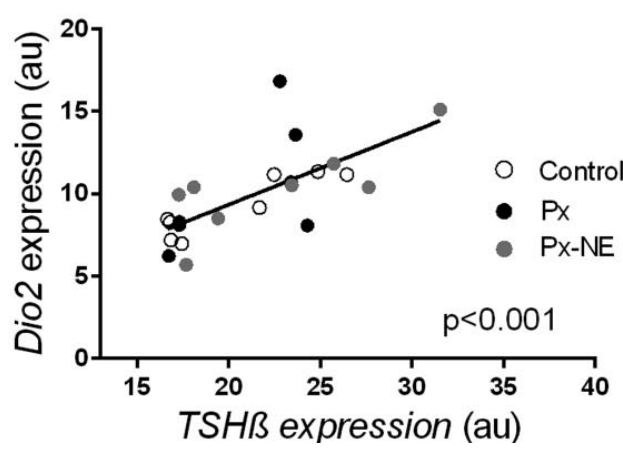

Figure 3. Melatonin-independent seasonal changes in gene expression in the pars tuberalis (PT) and the tanycytes. (A) Mean TSH $\beta$ labeling intensity in the PT and (B) mean dio2 labeling intensity in the periventricular zone of control, pinealectomized (Px), and pinealectomized nonentrainer (Px-NE) groups in the summer (white bars) and winter (black bars) states. Right: Representative images of (A) TSH $\beta$ and (B) dio $2 \mathrm{mRNA}$ labeling in Px summer and winter state animals. (C) Scatterplot showing the positive correlation between TSH $\beta$ and dio 2 mRNA expression in all animals of the study (Pearson $r=0.70 ; p<0.001$ ). au $=$ arbitrary units. Scale bars: $100 \mu \mathrm{m}$. ${ }^{*} p<0.05 ;{ }^{* *} p<0.01 ;{ }^{* * *} p<0.001$ for differences between summer and winter states within each group.

showed a higher number of rfrp-expressing cells in the summer than in the winter state (control, $t=2.919$, $p=0.01 ; \mathrm{Px}, t=2.581, p=0.019 ; \mathrm{Px}-\mathrm{NE}, t=5.774, p<$ 0.001). The number of rfrp-expressing cells was strongly correlated with TSH $\beta$ mRNA levels (Pearson $r=0.75 ; p<0.0001$; Fig 4B) and dio2 mRNA levels (Pearson $r=0.57 ; p=0.004 ;$ Fig $4 \mathrm{C}$ ), suggesting that the seasonal signal from the PT is transmitted to $r f r p$ neurons.

The number of kiss1-expressing cells in the ARC was similarly dependent on the season in which the animals were sampled $\left(F_{1,22}=21.61 ; p<0.001 ;\right.$ Fig. $\left.4 \mathrm{D}\right)$, but it was not influenced by the melatonin or entrainment state $\left(F_{2,17}=0.49 ; p=0.616\right)$. The post hoc analysis revealed a significant effect of seasonal state in the control and Px animals. The number of kiss1-expressing cells was higher in animals sampled in the winter, when testes are regressed, than in the summer state, when animals are sexually active (control, $t=3.377$, $p=0.004 ; \mathrm{Px}, t=2.681, p=0.016 ; \mathrm{Px}-\mathrm{NE}, t=1.99, p=0.062$; Fig. 4D). Additionally, a negative correlation was found between the number of kiss1-expressing cells 
A
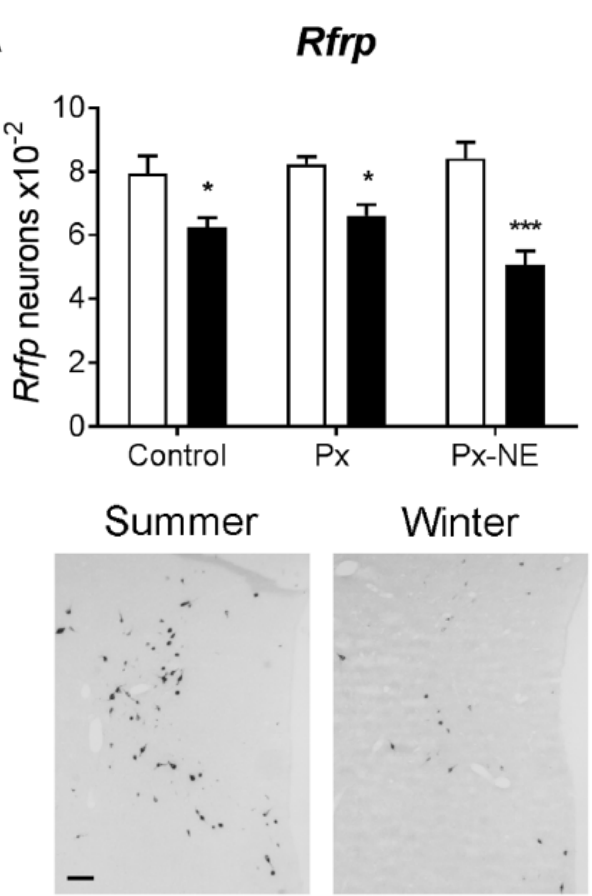

B

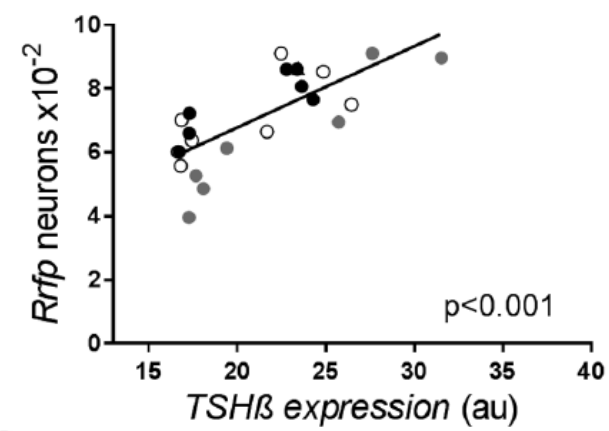

C

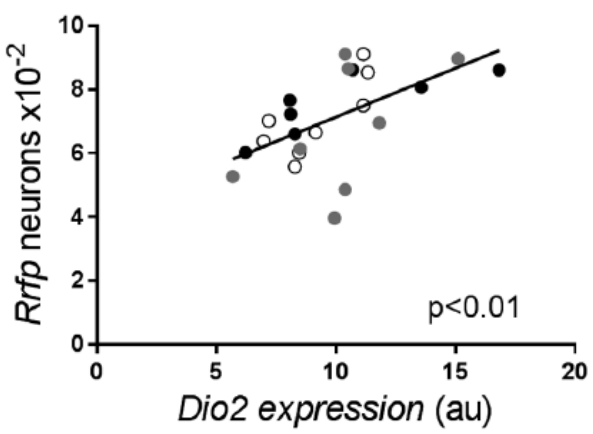

D

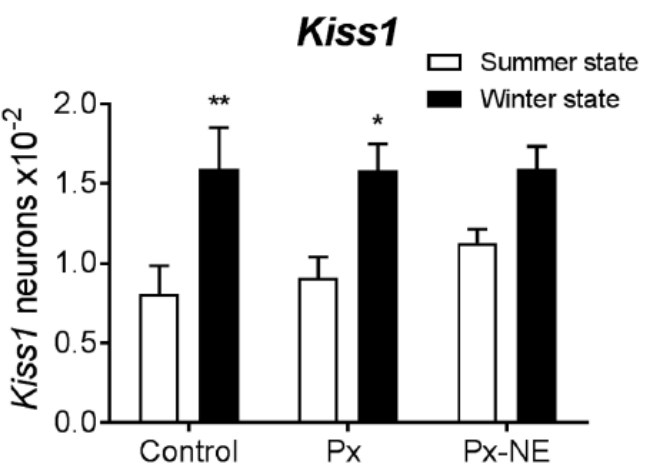

Summer

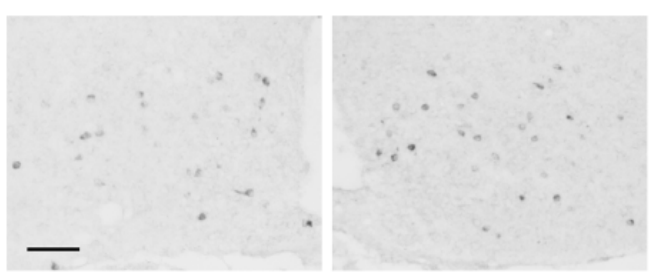

E

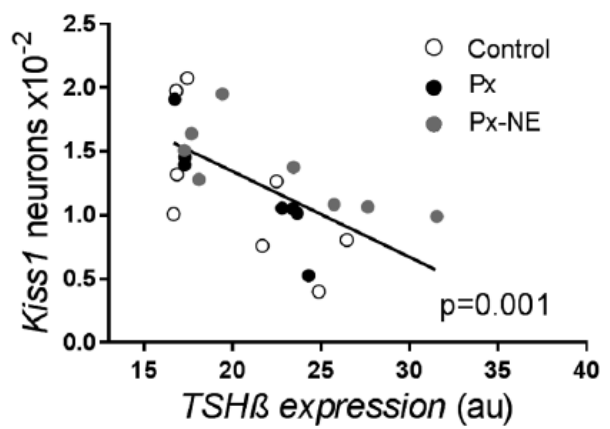

F

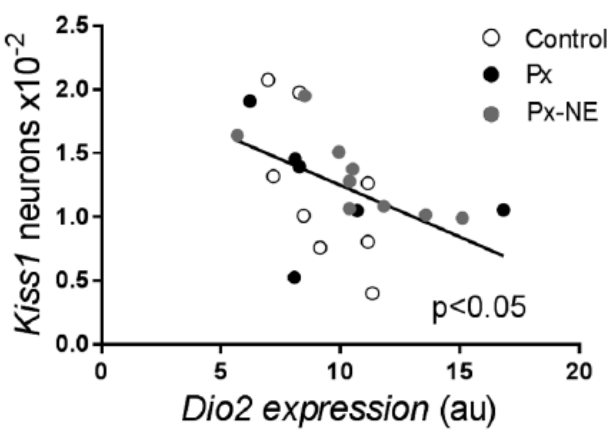

Figure 4. Melatonin-independent seasonal changes in RFamide gene expression in the hypothalamus. (A) Number of $r f r p$-expressing neurons in the DMH/VMH in control, Px, and Px-NE groups in the summer (white bars) and winter (black bars) state. Bottom: representative images of $r f r p$ mRNA labeling in Px summer and winter state animals. (B) Scatterplot showing the positive correlation between TSH $\beta$ mRNA expression and the number of $r f r p$-expressing neurons in all animals of the study (Pearson $r=0.75 ; p<0.0001$ ). (C) Scatterplot showing the positive correlation between dio 2 mRNA expression and the number of $r$ frp-expressing neurons in all animals of the study (Pearson $r=0.57 ; p=0.004$ ). (D) Number of kiss1-expressing neurons in the ARC of control, Px, and Px-NE groups in the summer (white bars) and winter (black bars) states. Bottom: representative images of kiss1 mRNA labeling in Px summer and winter state animals. (E) Scatterplot showing the negative correlation between TSH $\beta$ mRNA expression and the number of kiss1-expressing neurons in all animals of the study (Pearson $r=-0.64 ; p=0.001$ ). (F) Scatterplot showing the negative correlation between dio2 mRNA expression and the number of kiss1-expressing neurons in all animals of the study (Pearson $r=-0.49 ; p=0.017$ ). Scale bars: $100 \mu \mathrm{m}$. ${ }^{*} p<0.05$; ${ }^{* *} p<0.01 ;{ }^{* * *} p<0.001$ for differences between summer and winter states within each group. 
and TSH $\beta$ mRNA levels (Pearson $r=-0.64 ; p=0.001$; Fig. 4E), dio2 mRNA levels (Pearson $r=-0.49, p=0.02$; Fig. $4 \mathrm{~F})$, and the number of rfrp-expressing cells (Pearson $r=-0.52 ; p=0.011$; not shown).

Finally, none of the parameters analyzed was found to be significantly different between the winter animals in the Px and Px-NE groups, demonstrating that the time spent in the winter state has no effect on the levels of gene expression observed.

\section{DISCUSSION}

Annual regulation of TSH expression in the PT is the linchpin for the integration of environmental cues to synchronize seasonal physiology. The photoperiodic changes in circulating melatonin (Böckers et al., 1995; Dardente et al., 2010) and the endogenous circannual clock (Sáenz de Miera et al., 2014; Wood et al., 2015; Lomet et al., 2018) have been reported to drive the annual changes in PT TSH. Here we further show that the photoperiodic signal can synchronize the circannual rhythms in a melatonin-independent manner, and this phenomenon involves the regulation of PT TSH expression and, in turn, of the hypothalamic neuroendocrine pathway controlling reproduction. Thus, the PT arises as a key orchestrator of seasonal rhythms, where melatonin and photoperiod are integrated to synchronize the circannual clock-or the circannual regulation of TSH.

\section{Does the SCN Drive the Melatonin-independent Entrainment of the Circannual Clock?}

Locomotor activity is a well-known SCN rhythmic output notably affected by photoperiod in a similar way as melatonin but independently of the melatonin rhythm; suggesting that both locomotor and melatonin rhythms are driven by a common circadian signal, controlled by anatomically separated pathways (Hastings et al., 1987). In European hamsters, the sudden switch from the rather arrhythmic winter activity pattern to the rhythmic summer activity pattern is a strong seasonal marker induced by the circannual clock (Wollnik et al., 1991). It characterizes a so-called sensitive phase to SP (Monecke and Wollnik, 2005), during which photoperiodic information is processed (Saboureau et al., 1999), the circannual clock is reset (Monecke et al., 2009), and no nocturnal melatonin peak is observed (Vivien-Roels et al., 1997; Monecke and Wollnik, 2005). A temporal correlation between the summer to winter switch in the activity pattern and gonadal regression has been shown before in intact animals (Monecke et al., 2006). In our study, all animals of the Px group showed the typical rhythmic summer activity pattern at the same time as the control animals. The switch to winter physiology followed the switch from the summer activity pattern to the arrhythmic winter pattern by 4 weeks in both groups. The animals of the Px group showed identical properties of the activity pattern to the control group and identical physiological reactions. In the Px-NE group, the number of cycles in physiology also reflected the number of rhythmic summer patterns in activity. Thus, the present results suggest that the melatonin-independent photoperiodic entrainment may be an SCN output in the European hamster, and likely in other circannual species (Monecke et al., 2013; Monecke et al., 2014b).

Photoperiod is known to notably affect SCN rhythms. Neuronal firing in the SCN is altered by adaptation to LP or SP due to changes in the phase distribution of multiunit neuronal firing activity (Mrugala et al., 2000; VanderLeest et al., 2007) and in the strength of intercellular coupling (Buijink et al., 2016). Photoperiod also affects the daily rhythm of clock and clock-output gene expression, as observed in several species (Messager et al., 1999; Lincoln et al., 2002; Johnston et al., 2005), including the European hamster (Tournier et al., 2007). One study in Syrian hamsters indicated that these photoperiodic changes are independent of melatonin (Messager et al., 1999). All these data suggest that the photoperiodic signal generated by the SCN is entraining the different circannual rhythms at a common central location, probably the circannual clock.

It is intriguing that while all control animals showed entrainment to each phase of the modified photoperiodic cycle, only about half of the Px animals did. One explanation might be that a 6-month photoperiodic cycle is probably at the limit of the animals' range of entrainment. The animals not following each cycle may have temporarily lost track of the quickly changing photoperiod after the disturbance of pinealectomy, when the melatonin level decreased suddenly to a minimum. At recovery the photoperiodic cycle might have advanced too much to allow these animals to follow. This is supported by the fact that of all animals pinealectomized in this and a prior experiment (Monecke et al., 2013), the percentage of animals not entraining to each cycle became larger the later in the week they underwent surgery.

Whether the Px-NE animals entrained to each second photoperiodic cycle or presented free-running circannual rhythms remains unclear. Monecke et al. (2013) concluded that an entrainment to each second cycle is more likely than a free-run based on the period-length close to 365 days and a later reentrainment to each photoperiodic cycle observed in some of the animals. The current data support the same observation, with animals in the Px-NE group initiating 
the second summer phase of their body weight, reproductive cycle, and activity cycle when the Px and control animals initiated their third summer phase. The levels of gene expression observed in these animals are in agreement with both the photoperiodic conditions and the endogenous physiological state of the animals at the time of sampling (Sáenz de Miera et al., 2014), so that the current experiment does not allow differentiation between both possibilities.

\section{The PT-Hypothalamic System Entrains to the Melatonin-independent Photoperiodic Signal}

TSH is recognized as the canonical output of the PT for the transmission of the melatonin-mediated photoperiodic message (Hanon et al., 2008; Klosen et al., 2013) or the circannual signal (Sáenz de Miera et al., 2013, 2014; Wood et al., 2015) to control seasonal physiology. In the present study, TSH $\beta$ expression was upregulated in the summer state compared with the winter state animals, and its expression was identical whether the animals were pinealectomized or not, demonstrating that here melatonin is not required for photoperiodic entrainment. However, the seasonal change in melatonin is well known to induce photoperiodic fluctuations in TSH (Böckers et al., 1995); in fact, seasonality research initially focused on the PT because of the high concentration of melatonin receptors expressed in this anatomic structure (Williams et al., 1989; MassonPévet et al., 1994). Thus, the present results demonstrate that the photoperiodic information is able to reach the PT by alternative pathways to the circulating melatonin signal.

A compelling link between the PT and the hypothalamic regulation of dio2 expression is known to exist for the transmission of the photoperiodic message (Hanon et al., 2008; Klosen et al., 2013) and the endogenous control of circannual rhythms (Sáenz de Miera et al., 2013, 2014). Similarly, in the current study, dio 2 expression in the tanycytes was higher in the summer state compared with the winter state animals in the pinealectomized groups. Furthermore, dio2 expression strongly correlated with that of TSH $\beta$. Therefore, these results demonstrate that the photoperiodic pituitary-hypothalamic interplay is still intact in pinealectomized animals.

The level of rfrp gene expression in the $\mathrm{DMH} /$ VMH was higher in the summer state than in the winter state regardless of whether the animals were pinealectomized. Rfrp expression is known to be downregulated by melatonin in Syrian and Siberian hamsters by an indirect pathway mediated by TSH and DIO2 (Revel et al., 2008; Ubuka et al., 2012; Klosen et al., 2013). In the present experiment, the number of $r$ frp-expressing neurons strongly correlated with TSH $\beta$ and dio2 mRNA levels, suggesting that in both the presence and absence of melatonin, rfrp neurons integrate the photoperiodic information relayed by the TSH/DIO2 system.

Similarly, kiss1 expression in the arcuate nucleus of Syrian and Siberian hamsters is known to be downregulated by melatonin, while it is also subjected to a strong testosterone negative feedback (Revel et al., 2006; Ansel et al., 2010; Ubuka et al., 2012; RasriKlosen et al., 2017). In the current study, the level of kiss1 gene expression in the arcuate nucleus was lower in the summer state than in the winter state animals in both control and pinealectomized groups. This effect is probably due to the strong negative testosterone feedback in the reproductively active summer animals, as observed previously in this species (Sáenz de Miera et al., 2014), and in the Siberian hamster (Rasri-Klosen et al., 2017). The negative correlation found between TSH $\beta$, dio 2 mRNA levels, and kiss1 gene expression suggests that, as observed for rfrp expression, the photoperiodic signal transmitted by the TSH/DIO2 system is integrated by kiss1 neurons in the presence or absence of melatonin. Altogether, these results support the idea that the photoperiodic entrainment of the circannual signal is properly integrated by the melatonin-independent changes in TSH $\beta /$ Dio 2 expression and, in turn, by the neuroendocrine RFRP and kisspeptin-expressing neurons in the mediobasal hypothalamus and thus into the reproductive axis.

\section{Photoperiodic Melatonin-independent Pathway to the PT in Mammals}

No evidence is available regarding the pathway used by the photoperiodic message to reach the PT independently of melatonin in mammals. In nonmammalian species, photoperiodic synchronization is achieved independently of the melatonin signal via direct light perception by deep brain photoreceptors (Nakane et al., 2010), which project directly to the median eminence near the PT (Nakane et al., 2010). In mammals, it is well established that photoperiodic information is transmitted to brain nuclei via retinal projections (Hattar et al., 2003). We cannot disprove the existence of retinal projections to intermediate nuclei other than the SCN that eventually relay the photoperiodic information to the PT or alternative sources of light input to the mammalian brain; however, our activity data suggest that the $\mathrm{SCN}$ could be involved in the melatonin-independent photoperiodic entrainment of circannual rhythms.

One hypothesis is that the photoperiodic message reaches the PT via direct or indirect neural connections. In rats, a small number of SCN projections 
reach the median eminence (Swanson, 1975), while neurotransmitters such as adenosine or pituitary adenylate cyclase-activating polypeptide (PACAP), released in the median eminence, have been shown to act on PT cAMP expression and could be involved in the transmission of the photoperiodic message to the PT (Barrett et al., 2002, 2003). Adenosine signaling has been shown to interact with intrinsic PT endocannabinoids stimulated by long-days (Yasuo et al., 2010) in the regulation of prolactin secretion from Syrian hamster anterior pituitary (Yasuo et al., 2014). Whether these molecules affect TSH expression in the PT remains to be explored. Another possibility for a neural origin of this signal proposes that the photoperiodic message built in the $\mathrm{SCN}$ is directly transmitted to the arcuate nucleus, where it is integrated to seasonal neuroendocrine functions (Pévet et al., 2016). This idea is based on the existence of direct neuronal connections from the SCN to the arcuate nucleus (Saeb-Parsy et al., 2000; Guzmán-Ruiz et al., 2014) and on the observation of melatonin-independent photoperiodic cFOS expression in rat and European hamster arcuate nuclei (Jamali and Tramu, 1999; Pévet et al., 2016).

An alternative hypothesis is that a photoperiodmodulated hormonal signal other than melatonin could be acting on the PT to eventually modulate TSH expression. For instance, circulating glucocorticoids show a strong diurnal and photoperiodic variation in seasonal species (Canguilhem and Petrovic, 1974; Nexon et al., 2011) and have been shown to mediate photoperiodic regulation of gene expression in Syrian hamster brain (Nexon et al., 2011). In rat anterior pituitary, a large number of TSH-expressing cells express glucocorticoid receptors (Ozawa et al., 1999). In addition, long-term activation of the adrenal axis in sheep affects circannual rhythms in prolactin secretion in a phase-dependent manner (Hazlerigg and Lincoln, 2011).

Our results show a melatonin-independent transmission of the photoperiodic message to the PT, where it probably synchronizes the circannual clock (Sáenz de Miera et al., 2014). However, the nature of the photoperiodic message between the SCN and the $\mathrm{TSH} /$ dio2/RFamides system prevailing in this study remains to be elucidated. Melatonin infusions are still able to cause gonadal involution in European hamsters, however outside the sensitive phase during which the circannual clock can be reset (MassonPévet et al., 1987). Melatonin might thus serve for seasonal masking in case the circannual clock is poorly reset. As in circadian rhythms, masking might be of selective advantage also in seasonal rhythms: for example, by preventing animals from entering the winter season in the highly energy-consuming reproductive state, even if the circannual clock is poorly reset. In juvenile hamsters, melatonin is required for short-term timing of the puberty onset, before their circannual clock is reset (Monecke et al., 2014a). Thus, melatonin might play a role in short-term timing and in seasonal masking outside of the sensitive phases (around the equinoxes) in circannual species but not in the annual resetting of the circannual clock (Monecke et al., 2014b).

\section{Can This Model Help Us Distinguish Photoperiodic from Endogenous Circannual Effects in the PT?}

According to the nonparametric model of entrainment (Pittendrigh and Daan, 1976), the entrainment to only each second summer phase observed in the Px-NE arises from a mismatch between the photoperiodic signal and the endogenous circannual state. Thus, the current results open the possibility of distinguishing between the endogenous circannual message and its photoperiodic entrainment by studying the molecular mechanisms underlying TSH $\beta$ transcription and the downstream pathway in this paradigm at the time when physiology cycles are in antiphase with the photoperiodic cycle in the Px-NE animals (i.e., at the time when the Px-NE animals skipped the second summer phase). We expect that Px animals whose physiology is in antiphase with the accelerated photoperiod phase (i.e., animals in winter state during the LP phase of the photoperiodic cycle) will show PT and hypothalamic gene expression in agreement with their endogenous signal and thus match the prevailing seasonal physiology (i.e., low $T S H \beta$, dio2, and rfrp expression and high kiss1 gene expression in the animals in winter state and vice versa in the summer state), despite the prevailing photoperiodic signal. This hypothesis would benefit from an understanding of the mechanisms leading to TSH $\beta$ regulation in this model and how they differ from those described for melatonin-dependent photoperiodic entrainment. In melatonin-dependent photoperiodic entrainment, TSH $\beta$ expression is regulated by the transcription factor eya3, whose expression is subject to a double circadian- and melatonin-dependent regulation in seasonal and nonseasonal mammals (Dardente et al., 2010; Masumoto et al., 2010). Eya3 is also regulated spontaneously, without changes in photoperiod, in endogenously cycling sheep in a constant photoperiodic environment, although this occurs in the presence of a constant melatonin signal (Wood et al., 2015). In this regard, exploring whether eya3 expression is regulated by photoperiod in Px European hamsters and how it varies at the moment of mismatch between the photoperiodic signal and physiological state will help us understand the origin 
of the melatonin-independent signal and of the circannual message in the PT.

\section{CONCLUSIONS}

Our study demonstrates that photoperiod, via a melatonin-independent pathway, regulates TSH $\beta$ expression in the PT in European hamsters. This signal correlates with dio2 gene expression in the tanycytes and, in turn, with rfrp and kiss1 expression in the mediobasal hypothalamus and eventually affects reproduction and body weight. The photoperiodic message appears to be sufficient to drive the PT-hypothalamic neuroendocrine pathway, probably via prior entrainment of the circannual clock, which in turn entrains the circannual reproductive cycle in the absence of melatonin. Thus, the present results support the hypothesis that the PT and its communication with the hypothalamus are essential for the integration of circannual and photoperiodic information into seasonal physiology (Lincoln et al., 2006; Sáenz de Miera et al., 2013, 2014). We believe that in European hamsters, this melatonin-independent pathway is required for preserving central entrainment of circannual rhythms, since they do not produce melatonin when the circannual clock is reset (Vivien-Roels et al., 1997; Monecke and Wollnik, 2005; Monecke et al., 2009). Although this pathway has not been studied in other circannual mammals, it is likely to be present due to manifold similarities in entrainment, physiology, and behavior (Monecke et al., 2014b). To better understand the respective roles of melatonin and photoperiod in the entrainment of circannual rhythms, it might be interesting to analyze other outputs such as the prolactin secretion from the pituitary, a circannual rhythm known to be independent from hypothalamic control and dependent on melatonin input in sheep (Lincoln et al., 2006).

\section{ACKNOWLEDGMENTS}

This study was supported by grants from the following organizations: German Research Foundation (DFG Mo 1742/1-1), the Region of Alsace, the DREAL Alsace, the German Wildlife Foundation, the CNRS, and the University of Strasbourg Institute of Advanced Studies. The authors thank Daniel Bonn and Olivier Arnaud for expert animal care, Michel Saboureau for his help in pinealectomies, Agnes Degardin and Rim Bousalham for help in blood sampling for verification of pinealectomies, and Béatrice Bothorel and Christiane Calgary for the analysis of these blood samples. The study was conducted at the Chronobiotron (CNRS-UMS 3415).

\section{CONFLICT OF INTEREST STATEMENT}

The authors declare no potential conflicts of interest with respect to the research, authorship, and/or publication of this article.

\section{ORCID iD}

Cristina Sáenz de Miera (iD https://orcid.org/0000-00018047-035X

\section{REFERENCES}

Ancel C, Bentsen AH, Sébert ME, Tena-Sempere M, Mikkelsen JD, and Simonneaux V (2012) Stimulatory effect of RFRP-3 on the gonadotrophic axis in the male Syrian hamster: the exception proves the rule. Endocrinology 153:1352-1363.

Ansel L, Bolborea M, Bentsen AH, Klosen P, Mikkelsen JD, and Simonneaux V (2010) Differential regulation of Kiss1 expression by melatonin and gonadal hormones in male and female Syrian hamsters. J Biol Rhythm 25:81-91.

Barrett P, Messager S, Schuster C, Moar KM, Mercer JG, and Morgan PJ (2002) Pituitary adenylate cyclaseactivating polypeptide acts as a paracrine regulator of melatonin-responsive cells of the ovine pars tuberalis. Endocrinology 143:2366-2375.

Barrett P, Schuster C, Mercer J, and Morgan P (2003) Sensitization: a mechanism for melatonin action in the pars tuberalis. J Neuroendocrinol 15:415-421.

Barrett P, Ebling FJP, Schuhler S, Wilson D, Ross AW, Warner A, Jethwa P, Boelen A, Visser TJ, Ozanne DM, et al. (2007) Hypothalamic thyroid hormone catabolism acts as a gatekeeper for the seasonal control of body weight and reproduction. Endocrinology 148:3608-3617.

Böckers TM, Niklowitz P, Bockmann J, Fauteck JD, Wittkowski W, and Kreutz MR (1995) Daily melatonin injections induce cytological changes in pars tuberalis-specific cells similar to short photoperiod. J Neuroendocrinol 7:607-613.

Buijink MR, Almog A, Wit CB, Roethler O, Olde Engberink AHO, Meijer JH, Garlaschelli D, Rohling JHT, and Michel S (2016) Evidence for weakened intercellular coupling in the mammalian circadian clock under long photoperiod. PLoS One 11:1-16.

Canguilhem B and Petrovic A (1974) Effects of photoperiod and ambient temperature on circannual rhythms of body weight and adrenal cortex activity in European hamster (Cricetus cricetus). Arch Sci Physiol 28:113-126.

Dardente H, Hazlerigg DG, and Ebling FJP (2014) Thyroid hormone and seasonal rhythmicity. Front Endocrinol 5:Art. 19. 
Dardente H, Klosen P, Pévet P, and Masson-Pévet M (2003) MT1 melatonin receptor mRNA expressing cells in the pars tuberalis of the European hamster: effect of photoperiod. J Neuroendocrinol 15:778-786.

Dardente H, Wyse CA, Birnie MJ, Dupré SM, Loudon ASI, Lincoln GA, and Hazlerigg DG (2010) A molecular switch for photoperiod responsiveness in mammals. Curr Biol 20:2193-2198.

Guzmán-Ruiz M, Saderi N, Cazarez-Márquez F, GuerreroVargas NN, Basualdo MC, Acosta-Galván G, and Buijs RM (2014) The suprachiasmatic nucleus changes the daily activity of the arcuate nucleus $\alpha-\mathrm{MSH}$ neurons in male rats. Endocrinology 155:525-535.

Gwinner E (1986) Circannual Rhythms. Berlin, Germany: Springer-Verlag.

Hanon EA, Lincoln GA, Fustin JM, Dardente H, MassonPévet M, Morgan PJ, and Hazlerigg DG (2008) Ancestral TSH mechanism signals summer in a photoperiodic mammal. Curr Biol 18:30-32.

Hastings MH, Walker AP, and Herbert J (1987) Effect of asymmetrical reductions of photoperiod on pineal melatonin, locomotor activity and gonadal condition of male Syrian hamsters. J Endocrinol 114:221-229.

Hattar S, Lucas RJ, Mrosovsky N, Thompson S, Douglas RH, Hankins MW, Lem J, Biel M, Hofmann F, Foster RG, et al. (2003) Melanopsin and rod-cone photoreceptive systems account for all major accessory visual functions in mice. Nature 424:76-81.

Hazlerigg DG and Lincoln GA (2011) Hypothesis: cyclical histogenesis is the basis of circannual timing. J Biol Rhythm 26:471-485.

Henningsen JB, Gauer F, and Simonneaux V (2016) RFRP neurons-the doorway to understanding seasonal reproduction in mammals. Front Endocrinol 7:Art. 36.

Hoffman RA and Reiter RJ (1965) Rapid pinealectomy in hamsters and other small rodents. Anat Rec 153:19-22.

Jamali KA and Tramu G (1999) Control of rat hypothalamic pro-opiomelanocortin neurons by a circadian clock that is entrained by the daily light-off signal. Neuroscience 93:1051-1061.

Johnson CH, Elliott JA, Foster R, Honma KI, and Kronauer R (2004) Fundamental properties of circadian rhythms. In Chronobiology: Biological Timekeeping, Dunlap JC, Loros JJ, and DeCoursey PJ, eds, pp 67-105. Sunderland, MA: Sinauer Associates, Inc.

Johnston JD, Ebling FJP, and Hazlerigg DG (2005) Photoperiod regulates multiple gene expression in the suprachiasmatic nuclei and pars tuberalis of the Siberian hamster (Phodopus sungorus). Eur J Neurosci 21:2967-2974.

Karsch FJ, Robinson JE, Woodfill CJI, and Brown MB (1989) Circannual cycles of luteinizing-hormone and prolactin secretion in ewes during prolonged exposure to a fixed photoperiod-evidence for an endogenous reproductive rhythm. Biol Reprod 41:1034-1046.

Klosen P, Maessen X, and van den Bosch de Aguilar P (1993) PEG embedding for immunocytochemistry: application to the analysis of immunoreactivity loss during histological processing. J Histochem Cytochem 41:455-463.

Klosen P, Sébert ME, Rasri K, Laran-Chich M-P, and Simonneaux V (2013) TSH restores a summer phenotype in photoinhibited mammals via the RF-amides RFRP3 and kisspeptin. FASEB J 27:2677-2686.

Lincoln GA and Clarke IJ (1994) Photoperiodically-induced cycles in the secretion of prolactin in hypothalamopituitary disconnected rams-evidence for translation of the melatonin signal in the pituitary-gland. J Neuroendocrinol 6:251-260.

Lincoln GA, Clarke IJ, Hut RA, and Hazlerigg DG (2006) Characterizing a mammalian circannual pacemaker. Science 314:1941-1944.

Lincoln GA, Messager S, Andersson H, and Hazlerigg DG (2002) Temporal expression of seven clock genes in the suprachiasmatic nucleus and the pars tuberalis of the sheep: evidence for an internal coincidence timer. Proc Natl Acad Sci U S A 99:13890-13895.

Lomet D, Cognié J, Chesneau D, Dubois E, Hazlerigg D, and Dardente H (2018) The impact of thyroid hormone in seasonal breeding has a restricted transcriptional signature. Cell Mol Life Sci 75:905-919.

Masson-Pévet M, George D, Kalsbeek A, Saboureau M, Lakhdar-Ghazal N, and Pévet P (1994) An attempt to correlate brain areas containing melatonin-binding sites with rhythmic functions: a study in five hibernator species. Cell Tissue Res 278:97-106.

Masson-Pévet M, Pévet P, and Vivien-Roels B (1987) Pinealectomy and constant release of melatonin or 5-methoxytryptamine induce testicular atrophy in the European hamster (Cricetus cricetus, L.). J Pineal Res 4:79-88.

Masumoto K, Ukai-Tadenuma M, Kasukawa T, Nagano M, Uno KD, Tsujino K, Horikawa K, Shigeyoshi Y, and Ueda HR (2010) Acute induction of Eya3 by late-night light stimulation triggers TSH beta expression in photoperiodism. Curr Biol 20:2199-2206.

Messager S, Ross AW, Barrett P, and Morgan PJ (1999) Decoding photoperiodic time through Per1 and ICER gene amplitude. Proc Natl Acad Sci U S A 96:9938-9943.

Monecke S, Amann B, Lemuth K, and Wollnik F (2014a) Dual control of seasonal time keeping in male and female juvenile European hamsters. Physiol Behav 130:66-74.

Monecke S, Malan A, and Wollnik F (2006) Asymmetric control of short day response in European hamsters. J Biol Rhythm 21:290-300.

Monecke S, Saboureau M, Malan A, Bonn D, Masson-Pévet M, and Pévet P (2009) Circannual phase response curves to short and long photoperiod in the European hamster. J Biol Rhythm 24:413-426.

Monecke S, Sage-Ciocca D, Wollnik F, and Pévet P (2013) Photoperiod can entrain circannual rhythms in pinealectomized European hamsters. J Biol Rhythm 28:278290. 
Monecke S and Wollnik F (2004) European hamsters (Cricetus cricetus) show a transient phase of insensitivity to long photoperiods after gonadal regression. Biol Reprod 70:1438-1443.

Monecke S and Wollnik F (2005) Seasonal variations in circadian rhythms coincide with a phase of sensitivity to short photoperiods in the European hamster. J Comp Physiol B 175:167-183.

Monecke S, Wollnik F, and Pévet P (2014b) The circannual clock in the European hamster: how is it synchronized by photoperiodic changes? In Annual, Lunar and Tidal Clocks-Pattern and Mechanisms of Nature's Enigmatic Rhythms, Numata H and Helm B, eds, pp 293-326. Tokyo: Springer, Japan.

Moore RY (1996) Neural control of the pineal gland. Behav Brain Res 73:125-130.

Mrugala M, Zlomanczuk P, Jagota A, and Schwartz WJ (2000) Rhythmic multiunit neural activity in slices of hamster suprachiasmatic nucleus reflect prior photoperiod. Am J Physiol Regul Integr Comp Physiol 278:R987-R994.

Nakane Y, Ikegami K, Ono H, Yamamoto N, Yoshida S, Hirunagi K, Ebihara S, Kubo Y, and Yoshimura T (2010) A mammalian neural tissue opsin (Opsin 5) is a deep brain photoreceptor in birds. Proc Natl Acad Sci U S A 107:15264-15268.

Nexon L,Sage D,PévetP, and RaisonS(2011)Glucocorticoidmediated nycthemeral and photoperiodic regulation of tph2 expression. Eur J Neurosci 33:1308-1317.

Nisimura T and Numata H (2001) Endogenous timing mechanism controlling the circannual pupation rhythm of the varied carpet beetle Anthrenus verbasci. J Comp Physiol A 187:433-440.

Nuesslein-Hildesheim B, O’Brien JA, Ebling FJP, Maywood ES, and Hastings MH (2000) The circadian cycle of mPER clock gene products in the suprachiasmatic nucleus of the Siberian hamster encodes both daily and seasonal time. Eur J Neurosci 12:2856-2864.

Ozawa H, Ito T, Ochiai I, and Kawata M (1999) Cellular localization and distribution of glucocorticoid receptor immunoreactivity and the expression of glucocorticoid receptor messenger RNA in rat pituitary gland: a combined double immunohistochemistry study and in situ hybridization histochemical analysis. Cell Tissue Res 295:207-214.

Pengelley ET and Asmundson SJ (1974) Circannual rhythmicity in hibernating mammals. In Circannual Clocks: Annual Biological Rhythms, Pengelley ET, ed, pp 95-160. London: Academic Press.

Perreau-Lenz S, Kalsbeek A, Pévet P, and Buijs RM (2004) Glutamatergic clock output stimulates melatonin synthesis at night. Eur J Neurosci 19:318-324.

Pévet P, Bouaouda H, Monecke S, Mendoza J, EL Allali $\mathrm{K}$, and Challet E (2016) Control of seasonality by photoperiodic changes: are the arcuate nuclei involved? In Updates on Integrative Physiology and Comparative
Endocrinology, Haldar C, Sameer G, and Goswami S, eds, pp 275-295. Varanasi, India: Publication Cell Press and Publication Division Banaras Hindu University.

Pittendrigh CS and Daan S (1976) A functional analysis of circadian pacemakers in nocturnal rodents. IV. Entrainment: pacemaker as clock. J Comp Physiol A 106:291-331.

Rasri-Klosen K, Simonneaux V, and Klosen P (2017) Differential response patterns of kisspeptin and RFRP to photoperiod and sex steroid feedback in the Djungarian hamster (Phodopus sungorus). J Neuroendocrinol 3:1-13.

Revel FG, Saboureau M, Masson-Pévet M, Pévet $P$, Mikkelsen JD, and Simonneaux V (2006) Kisspeptin mediates the photoperiodic control of reproduction in hamsters. Curr Biol 16:1730-1735.

Revel FG, Saboureau M, Pévet P, Simonneaux V, and Mikkelsen JD (2008) RFamide-related peptide gene is a melatonin-driven photoperiodic gene. Endocrinology 149:902-912.

Saboureau M, Masson-Pévet M, Canguilhem B, and Pévet $P$ (1999) Circannual reproductive rhythm in the European hamster (Cricetus cricetus): demonstration of the existence of an annual phase of sensitivity to short photoperiod. J Pineal Res 26:9-16.

Saeb-Parsy K, Lombardelli S, Khan FZ, McDowall K, Au-Yong ITH, and Dyball REJ (2000) Neural connections of hypothalamic neuroendocrine nuclei in the rat. J Neuroendocrinol 12:635-648.

Sáenz de Miera C, Hanon EA, Dardente H, Birnie MJ, Simonneaux V, Lincoln GA, and Hazlerigg DG (2013) Circannual variation in thyroid hormone deiodinases in a short-day breeder. J Neuroendocrinol 25:412-421.

Sáenz de Miera C, Monecke S, Bartzen-Sprauer J, LaranChich M-P, Pévet P, Hazlerigg DG, and Simonneaux V (2014) A circannual clock drives expression of genes central for seasonal reproduction. Curr Biol 24:15001506.

Simonneaux V, Ancel C, Poirel VJ, and Gauer F (2013) Kisspeptins and RFRP-3 act in concert to synchronize rodent reproduction with seasons. Front Neurosci 7:22.

Skene DJ, Masson-Pevet M, and Pevet P (1993) Seasonal changes in melatonin binding sites in the pars tuberalis of male European hamsters and the effect of testosterone manipulation. Endocrinology 132:1682-1686.

SmithJT, Coolen LM, Kriegsfeld LJ, Sari IP,Jafarzadehshirazi MR, Maltby M, Bateman K, Goodman RL, Tilbrook AJ, Ubuka T, et al (2008) Variation in kisspeptin and RFamide-related peptide (RFRP) expression and terminal connections to gonadotropin-releasing hormone neurons in the brain: a novel medium for seasonal breeding in the sheep. Endocrinology 149:5770-5782.

Smith JT, Li Q, Pereira A, and Clarke IJ (2009) Kisspeptin neurons in the ovine arcuate nucleus and preoptic area are involved in the preovulatory luteinizing hormone surge. Endocrinology 150:5530-5538. 
Swanson LW (1975) The efferent connections of the suprachiasmatic nucleus of the hypothalamus. J Comp Neurol 160:1-12.

Talbi R, Klosen P, Laran-Chich MP, El Ouezzani S, and Simonneaux V (2016) Coordinated seasonal regulation of metabolic and reproductive hypothalamic peptides in the desert jerboa. J Comp Neurol 524:3717-3728.

Tournier BB, Dardente H, Simonneaux V, Vivien-Roels B, Pévet P, Masson-Pévet M, and Vuillez P (2007) Seasonal variations of clock gene expression in the suprachiasmatic nuclei and pars tuberalis of the European hamster (Cricetus cricetus). Eur J Neurosci 25:1529-1536.

Tsutsui K, Bentley GE, Bedecarrats G, Osugi T, Ubuka T, and Kriegsfeld LJ (2010) Gonadotropin-inhibitory hormone $(\mathrm{GnIH})$ and its control of central and peripheral reproductive function. Front Neuroendocrinol 31:284-295.

Ubuka T, Inoue K, Fukuda Y, Mizuno T, Ukena K, Kriegsfeld LJ, and Tsutsui K (2012) Identification, expression, and physiological functions of Siberian hamster gonadotropin-inhibitory hormone. Endocrinology 153:373-385.

VanderLeest HT, Houben T, Michel S, Deboer T, Albus H, Vansteensel MJ, Block GD, and Meijer JH (2007) Seasonal encoding by the circadian pacemaker of the SCN. Curr Biol 17:468-473.

Vivien-Roels B, Pévet P, Masson-Pévet M, and Canguilhem B (1992) Seasonal variations in the daily rhythm of pineal gland and/or circulating melatonin and 5-methoxytryptophol concentrations in the European hamster, Cricetus cricetus. Gen Comp Endocr 86: 239-247.
Vivien-Roels B, Pitrosky B, Zitouni M, Malan A, Canguilhem B, Bonn D, and Pévet P (1997) Environmental control of the seasonal variations in the daily pattern of melatonin synthesis in the European hamster, Cricetus cricetus. Gen Comp Endocr 106:85-94.

Vogel G (2005) A powerful first KiSS-1. Science 309:551-552.

Williams LM, Morgan PJ, Hastings MH, Lawson W, Davidson G, and Howell HE (1989) Melatonin receptor sites in the Syrian hamster brain and pituitary. localization and characterization using [125I] lodomelatonin. J Neuroendocrinol 1:315-320.

Wollnik F, Breit A, and Reinke D (1991) Seasonal change in the temporal organization of wheel-running activity of the European hamster, Cricetus cricetus. Naturwissenschaften 78:419-422.

Wood S, Christian HC, Miedzinska K, Mcneilly AS, Burt DW, and Loudon ASI (2015) Binary switching of calendar cells in the pituitary defines the phase of the circannual cycle in mammals. Curr Biol 25:2652-2662.

Wood S and Loudon A (2018) The pars tuberalis: the site of the circannual clock in mammals? Gen Comp Endocr. 258: 222-235.

Yasuo S, Fischer C, Bojunga J, ligo M, and Korf HW (2014) 2-Arachidonoyl glycerol sensitizes the pars distalis and enhances forskolin-stimulated prolactin secretion in Syrian hamsters. Chronobiol Int 31:337-342.

Yasuo S, Koch M, Schmidt H, Ziebell S, Bojunga J, Geisslinger G, and Korf HW (2010) An endocannabinoid system is localized to the hypophysial pars tuberalis of Syrian hamsters and responds to photoperiodic changes. Cell Tissue Res 340:127-136. 